\title{
Fermentative Gas Production of Different Feeds Collected During Wet and Dry Seasons when Incubated with Rumen Fluid from Timor Deer (Cervus timorensis)
}

\author{
Arifuddin $\mathrm{MS}^{1}$, Utomo $\mathrm{R}^{2}$, Hartadi $\mathrm{H}^{2}$, Damry ${ }^{1}$ \\ ${ }^{1}$ Department of Animal Science, Tadulako University, Palu \\ 2 Department of Animal Feed and Nutrition, Gadjah Mada University, Yogyakarta \\ sadik_arifuddin@yahoo.com
}

\begin{abstract}
An experiment was done to investigate rumen microbial fermentation of various feeds comonly given to Timor deer (Cervus timorensis) using the in vitro gas production technique. Seven forage feed sample (Sesbania grandiflora, Leucaena leucocephala, Glyricidia sepium, Zea mays, Ipomea aquatica, Pennisetum purpureum, and native grass) collected during dry and wet seasons and three concentrate feed samples (rice bran, copra meal and tofu waste) were dried and ground. The feed sample ( $200 \mathrm{~g})$ was transferred into incubation syringe which was then added with incubation medium (mixture of rumen fluid and buffer solution). The rumen fluid was collected from 2 Timor deer using a trokar technique. Incubation was run for $72 \mathrm{~h}$, and gas production was read at 2, 4, 6, 12, 24, 48, and $72 \mathrm{~h}$ of incubation. Data were fitted to an exponential equation generally used in similar in vitro gas production studies. Results of the study indicated that there was an effect of season on fermentation parameters (values of $a, b$ or c) for the same feed, but this effect was not consistent from one feed to another. From data of total and cummulative gas productions, it was indicated that Zea mays in either dry or wet season showed the highest, while Leucaena leucocephala exhibited the lowest gas production compared to other feeds tested.
\end{abstract}

Key Words: Cervus Timorensis, Gas Poduction, Wet Season, Dry Season, Fermentation

\section{INTRODUCTION}

Microbial digestion in the rumen of feed substances consumed by ruminants involves degradation of the feed into simpler components and subsequent fermentation of the resulting products. Degradation results in the formation of monomers, such as glucose which is produced from carbodyrate degradation and amino acids which are formed from peptides or protein. These degradation end products then undergo microbial fermentation which results in the production of volatile fatty acids, VFA (mainly acetate, propionate, and butyrate), adenosine triphosphate (ATP) and fermentative gas. The ATP generated during the fermentation is the main energy source used by the rumen microbes for both cell maintenance and growth. Gas, mainly methane $\left(\mathrm{CH}_{4}\right)$ and carbon dioxides $\left(\mathrm{CO}_{2}\right)$ produced during microbial fermentation, normally leaves the rumen via eructation. From nutritional point of view, formation of gas during microbial fermentation is a loss of potential energy which may otherwise be available to animals. It has been accepted that as much as $7 \%$ of digestible energy contents of feed in ruminants is lost as methane (McDonald et al. 2002).

Gas produced during fermentation of a feed in the rumen is closely related to the degradation of the feed and has thus been used as an indicator of microbial feed degradation in the rumen. Gas production technique has been developed in such as a way to obtain more reliable and accurate predictions of feed degradation in the rumen. For example, a pressure tranducer was introduced by Theodorou et al. (1994) into the gas production technique to determine dynamics of fermentation. Beside serving as a 
technique for estimating feed degradation, gas production has also been used to indicate microbial activities and environment in the rumen. This is particularly true for wild ruminants where conventional feed degradation studies are more difficut to conduct than for domesticated ones because of, for example, limited availability of animal as rumen fluid donor.

Timor deer (Cervus timorensis) is a wild ruminant that has gained more attention due to its economic potentials. However, limited study has been done to address fermentation pattern of feed in the rumen of Timor deer. This present study was designed to investigate microbial degradation in the rumen of Timor deer of different feeds commonly feed to this animal, using the in vitro gas production technique.

\section{MATERIAL AND METHODS}

\section{Feed sample preparation}

Seven forage feed samples (Sesbania grandiflora, Leucaena leucocephala, Glyricidia sepium, Zea mays, Ipomea aquatica, Pennisetum purpureum, and native grass) were collected during dry and wet seasons in Palu as well as three concentrate feed samples (rice bran, copra meal and tofu waste). These are the feeds that are normally given to Timor deer (Cervus timorensis) in this area. All the feed samples were dried to a constant weight in an oven at $60^{\circ} \mathrm{C}$ for at least $48 \mathrm{~h}$. The dried samples were then ground to pass 1 $\mathrm{mm}$ sieve, and brought to the Department of Animal Feed and Nutrition, Faculty of Animal Husbandry, Gadjah Mada University for an in vitro gas production studies.

\section{Rumen fluid collection and incubation medium preparation}

Rumen fluid was obtained from two adult Timor deer (Cervus timorensis) that were kept at Bunder Flora and Fauna Station, District of Gunung Kidul, about $30 \mathrm{~km}$ from Yogyakarta. Prior to rumen fluid collection, the donor animals were separated from their counterparts and kept on a feed consisting of Zea mays leaves and rice bran. The forage feed as well as fresh drinking water were provided ad libitum to the animals, while the the rice bran supplement was given once daily in the morning.

The rumen fluid was collected using a trokar technique. The donor animals were locally anesthetized by injecting them with $2 \mathrm{ml}$ of Procain $\mathrm{HCl}$. Small opening was made at the skin on left hand side of the animals at the intersection point of about $10 \mathrm{~cm}$ distant from the last rib and $10 \mathrm{~cm}$ from the backbone. This was done carefully to prevent damage on the rumen wall. The trokar was immediately applied to the rumen wall and rumen fluid was drawn with a syringe through a tube inserted via the trokar. Collected rumen fluid was transferred into a container and placed in a thermos.

Incubation medium was prepared by mixing rumen fluid with a buffer solution with a mixing ratio of $1: 2$. The buffer solution $(1,000 \mathrm{ml})$ was prepared by transferring $474 \mathrm{ml}$ of aquadest into a flask, to which was then added $0.12 \mathrm{ml}$ of macromineral solution (Solution A: $5.7 \mathrm{~g}$ of $\mathrm{Na}_{2} \mathrm{PO}_{4}+6.2 \mathrm{~g}$ of $\mathrm{KH}_{2} \mathrm{PO}_{4}+0.6 \mathrm{~g}$ of $\mathrm{MgSO}_{4} 7 \mathrm{H}_{2} \mathrm{O}$ in 11 of aquadest), $237 \mathrm{ml}$ of micromineral solution (Solution B: $13.2 \mathrm{~g}$ of $\mathrm{CaCl}_{2} 2 \mathrm{H} 2 \mathrm{O}+10 \mathrm{~g}$ of $\mathrm{MnCl}_{2} 4 \mathrm{H}_{2} \mathrm{O}+1 \mathrm{~g}$ of $\mathrm{CoCl}_{2} 6 \mathrm{H}_{2} \mathrm{O}+0.8 \mathrm{~g} \mathrm{FeCl} 26 \mathrm{H} 2 \mathrm{O}$ in $100 \mathrm{ml}$ of aquadest), $237 \mathrm{ml}$ of buffer solution (35 $\mathrm{g}$ of $\mathrm{NaHCO}_{2}+4 \mathrm{~g}$ of $\left(\mathrm{NH}_{4}\right)_{2} \mathrm{HCO}_{3}$ in 11 of aquadest), and $1.22 \mathrm{ml}$ of $0.1 \%$ resazurin solution and a reducing solution ( $2 \mathrm{ml}$ of $\mathrm{NaOH} 1 \mathrm{~N}+285 \mathrm{mg}$ of $\left.\mathrm{Na}_{2} \mathrm{~S}_{7} \mathrm{H}_{2}\right)+47,5 \mathrm{ml}$ of aquadest). The solution was placed on a hot plate set at $38^{\circ} \mathrm{C}$ and was thoroughly mixed with an aid of magnetic stirrer. The solution was flushed with $\mathrm{CO}_{2}$ and added with more reducing solution until total volume of reducing solution used was $49.5 \mathrm{ml}$. Mixing was continued 
until the solution was colourless and rumen fluid $(457.5 \mathrm{ml})$ was then finally included into the solution. All the process was done under anaerobic condition (Menke \& Steingass 1988).

\section{Procedure of incubation and analysis}

Thirty $\mathrm{ml}$ of incubation solution was placed in the incubation syringe containing $200 \mathrm{~g}$ of ground feed sample. Carbondioxide was once more flushed into the syringe before its plunger and lid were carefully placed in position. Initial plunger position on the syringe scale was then read as zero time $\left(\mathrm{V}_{0}\right)$ and the incubation syringe was placed at a temperature of $39^{\circ} \mathrm{C}$. A blank incubation syringe (syringe containing incubation medium only) was also included in the run. The incubation was run for $72 \mathrm{~h}$, and the amount of fermentation gas produced was read at 2, 4, 6, 12, 24, 48, and $72 \mathrm{~h}$ of incubation.

Data of fermentative gas production were fitted with the following exponential equation (Orskov \& McDonald 1979) using the Neway Excel Program (Chen 1995) and presented descriptically:

$$
P=a+b\left(1-e^{-c t}\right)
$$

Where P: volume $(\mathrm{ml})$ of gas produced at t time

a: volume (ml) of gas produced from rapidly degradable feed components

b: volume $(\mathrm{ml})$ of gas produced from less rapidly degradable feed components

c: rate of gas production

$\mathrm{t}$ : incubation time

\section{RESULTS AND DISCUSSION}

Gas produced when feeds incubated with rumen fluid indicates the process of microbial fermentation of the feeds through which the rumen microbes extract energy from the feeds for themselves. Measuring fermentative gas production is relatively simple yet it provides a reliable estimate of feed degradation and fermentation in the rumen. Not only does gas production technique measure the total gas produced at the end of incubation, but it also provides a possibility to measure dynamics of fermentation over the course of incubation. With this technique, data are usually fitted with the exponential equation Orskov \& McDonald (1979) and fermentation parameters (a, b and c) are obtained.

\section{Fermentation parameters}

Data of gas production parameters for feed samples commonly fed to Timor deer when incubated with rumen fluid are presented in Table 1.

Fraction a indicates the amount of gas produced from rapidly fermented fraction of a feed sample. This is the fraction that rumen microbes first ferment for them to obtain energy for immediate requirements. Results of this study indicated that there was a difference in the a value between wet and dry season for the same forage feed sample. Generally, the a value for a feed sample collected during wet season was higher than the one obtained during dry season, while the a value for the dry season was often exhibited a negative value.

The higher a value for wet than for dry feed sample could be interpreted that there was more degradable fraction of feed in wet than in dry season. Since the more degradable feed 
Tabel 1.Gas fermentation parameters of different feed samples collected during wet and dry seasons when incubated with rumen fluid from Timor deer (Cervus timorensis)

\begin{tabular}{lcccc}
\hline \hline & \multicolumn{4}{c}{ Parameters } \\
\cline { 2 - 5 } Feed samples (season) & $\begin{array}{c}\mathrm{a}(\mathrm{m} 1 / 200 \\
\mathrm{mg} \mathrm{DM})\end{array}$ & $\begin{array}{c}\mathrm{b}(\mathrm{ml} / 200 \\
\mathrm{mg})\end{array}$ & $\mathrm{c} \mathrm{(ml/h)}$ & $\begin{array}{c}\mathrm{a}+\mathrm{b}(\mathrm{m} 1 / 200 \\
\mathrm{mg} \mathrm{DM})\end{array}$ \\
\hline Sesbania grandiflora (dry) & -1.769 & 72.169 & 0.063 & 70.399 \\
Sesbania grandiflora (wet) & 1.379 & 63.900 & 0.059 & 65.279 \\
Leucaena leucocephala (dry) & 4.642 & 49.041 & 0.035 & 53.683 \\
Leucaena leucocephala (wet) & 5.287 & 52.487 & 0.047 & 57.775 \\
Glyricidia sepium (dry) & 1.975 & 65.126 & 0.063 & 67.101 \\
Glyricidia sepium (wet) & 2.348 & 62.201 & 0.061 & 64.549 \\
Zea mays (leaves, dry) & 4.924 & 105.826 & 0.044 & 110.749 \\
Zea mays (leaves, wet) & 5.877 & 83.343 & 0.039 & 89.219 \\
Water spinach, Ipomea aquatica (dry) & -4.995 & 74.487 & 0.057 & 69.491 \\
Water spinach, Ipomea aquatica (wet) & 5.877 & 83.343 & 0.039 & 89.219 \\
King grass, Pennisetum purpureum (dry) & -1.579 & 73.233 & 0.038 & 71.653 \\
King grass, Pennisetumpurpureum(wet) & 6.353 & 74.852 & 0.041 & 81.205 \\
Native grasses (dry) & 1.614 & 66.482 & 0.039 & 68.096 \\
Native grasses (wet) & 2.348 & 62.201 & 0.061 & 64.549 \\
Rice bran & 4.769 & 54.969 & 0.060 & 59.738 \\
Copra meal & 2.401 & 68.816 & 0.063 & 71.217 \\
Tofu waste & -1.923 & 83.018 & 0.054 & 81.094 \\
\hline
\end{tabular}

component consists mainly of rapidly available carbohydrates located inside the plant cells, the plant appears to switch its metabolic pathways to store more degradable carbohidrate inside cell rather than structural components of the cell wall. Negative a values were observed for some feeds from samples collected during dry season. This is not correct but it may have indicated the very small amounts of fraction that was rapidly degradable and fermentable in these samples Orskov \& Ryle (1990). Practical implication we may draw from this data is that there may be a need to provide more digestible and fermentable substrate for rumen microbes during dry season feeding.

Fraction $b$ indicates the proportion of feed organic matter that is degradable and fermentable at slower rates compared to the fraction a. This is the fraction that rumen microbes ferment after the rapidly fermentable organic matter has been depleted and become the major source of gas generated during the course of fermentation. In this study, there was no distinctive difference in the value of $b$ fraction between forage feed sample collected during wet and dry season, with a mean of $70.62( \pm 14.234) \mathrm{ml} / 200 \mathrm{~g} \mathrm{DM}$. For concentrate feeds, the mean $( \pm$ STDEV) value of $\mathrm{b}$ fraction was $68.93( \pm 14.025) \mathrm{ml} / 200 \mathrm{~g}$ DM. Fraction $\mathrm{c}$ indicates the mean rate of fermentative gas prodution from degraded feed organic matter, and in this study is expressed in ml per h. This fraction can be taken to reflect rates of feed breakdown in the rumen due to microbial degradation.

\section{Total and dynamics of gas production}

Total gas production at end point of $72 \mathrm{~h}$ fermentation and cummulative gas production profile during the course of fermentation are presented in Figure 1 and 2, 
respectively. Cummulative gas production profile is particularly helpful in making an overall comparison on the dynamics of gas production generated by different feeds during a given course of fermentation.

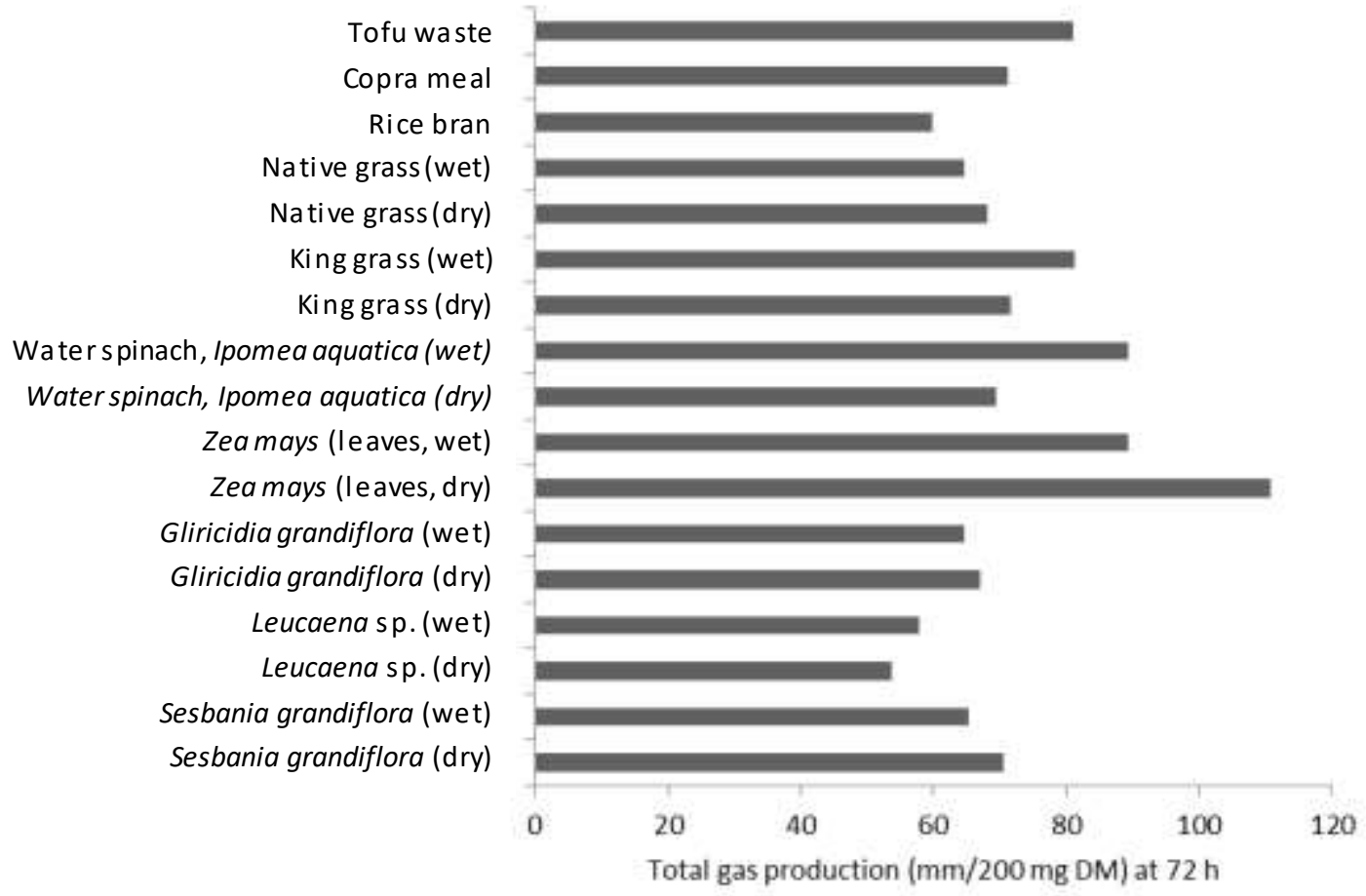

Figure 1. Total fermentative gas production at $72 \mathrm{~h}$ of incubation with rumen fluid from Timor deer (Cervus timorensis) of different feed samples collected during wet and dry seasons

It can clearly be seen from both figures that Zea mays leaves collected during dry season produced the highest volume of fermentative gas and this was followed by the same feed collected during wet season, while Leucaena leucocephala in dry season generated the least volume of fermentative gas. The highest gas volume produced from Zea may leaves was probably due to adaptation developed by rumen microbial consortium to degrade and ferment this feed. Animals used as rumen fluid donor were maintained on a diet based on Zea mays leaves, and it is expected that microbial population in the rumen has adapted to this feed profile. Differences in the fermentative gas production between dry and wet seasons for Zea mays leaves may have been due the feed factor in that there was more fermentable fraction present in this feed during dry than wet season.

Lowest gas production was observed for Leucaena leucocephala, either collected at wet or at dry season. This was probably due to the presence secondary components in this tree legume, i.e. tannin and mimosine, which prevent optimum fermentation of the feed by the rumen microbes. Gas productions for othe feeds, including three concentrate feed samples tested, was in between those for Zea mays leaves and Leucaena leucocephala. 


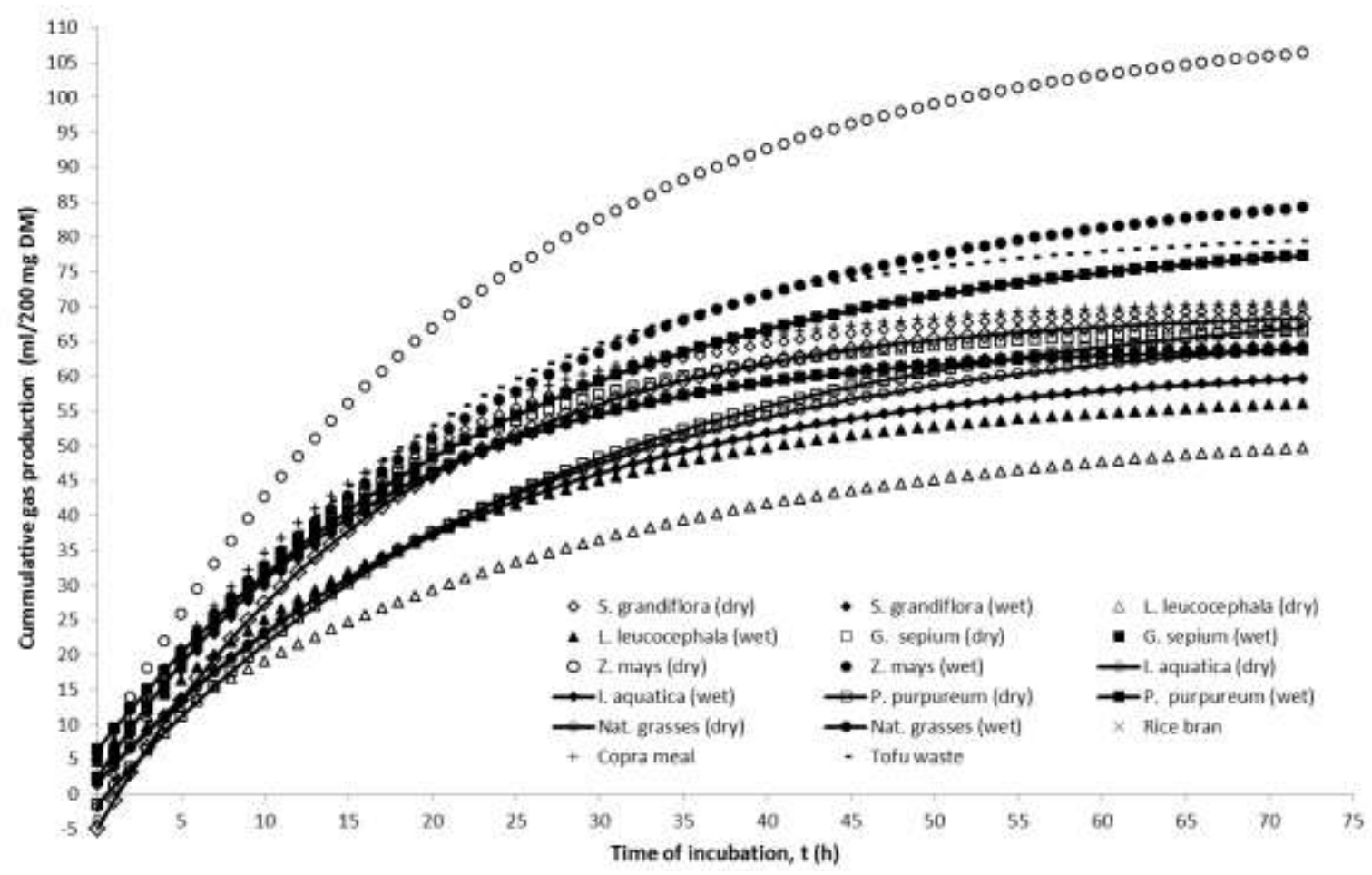

Figure 2. Cummulative gas production profiles of different feed samples collected during wet and dry seasons when incubated with rumen fluid from Timor deer (Cervus timorensis) for $72 \mathrm{~h}$

\section{CONCLUSION}

It can be concluded that fermentation and degradation of a feed in the rumen of Timor deer (Cervus timorensis) is different during wet and dry seasons, but the effect of season on feed fermentability varies from one feed to another. Among the commonly feeds given to Timor deer (Cervus timorensis) tested in the present study, the highest gas production was obtained for Zea mays leaves while the lowest one was exhibited by Leucaena leucocephala.

\section{ACKNOWLEDGEMENT}

We would like to thank the Directorate General of Higher Education, National Education Department, for financial support through the 2008 Hibah Bersaing grant and the Rector of Tadulako University.

\section{REFERENCES}

Chen BX. 1995. Neway exel: An axel application programme for processing feed degradability data. User Manual. Aberdeen (UK): International Feed Resources Unit, Rowet Research Institute Bucksburn.

McDonald P, Edwards RA, Greenhalgh JFD, Morgan CA. 2002. Animal Nutrition. Edinburgh Gate (UK): Pearson Education Ltd.

Menke KH, H Steingass. 1988. Estimation of energetic feed value obtained from chemical analysis and in vitro gas production. Anim Res Dev. 28:7-25. 
Orskov ER, Ryle M. 1990. Energy nutrition in ruminants. Elsevier Applied Science, London and New York.

Orskov ER, McDonald I. 1979. The estimation of protein degradability in the rumen from incubation measurements weighted according to rate of passage. J Agric Sci. 92:499-503.

Theodorou MK, Williams BA, Dhanoa MS, McAllen ADB, France J. 1994. A simple gas preduction method using a pressure tranducer to determine the fermentation kinetics of rumen fluids. Anim Feed Sci Technol. 48:185-197.

\section{DISCUSSION}

\section{Question}

What are considerations of using rumen fluid from deer to measure gas production, because it is difficult to take and handle the animals?

\section{Answer}

Using local anesthesia; other consideration like to compare with gas production with the other source of rumen fluid 